\title{
Air Pollution, Health and Ethics
}

\author{
Robin Attfield* \\ Department of Philosophy, Cardiff University, United Kingdom \\ *Corresponding author: Robin Attfield, Department of Philosophy, Cardiff University, United Kingdom. \\ To Cite This Article: Robin Attfield. Air Pollution, Health and Ethics. Am J Biomed Sci \& Res. 2019 - 3(1). AJBSR.MS.ID.000633. \\ DOI: 10.34297/AJBSR.2019.03.000633
}

Received: May 06, 2019 | Published: May 16, 2019

\section{Introduction}

Recent findings about nitrogen dioxide pollution in Britain and about particulate pollution worldwide raise ethical issues about the protection of human (and animal) health [1]. Many urban areas of Britain have been found to have illegally high levels of $\mathrm{NO}_{2}$. But it turns out that there is a world-wide problem with particulates, particularly in large towns and cities in Third world countries, as well as in much of Europe and North America. In many cases diesel engines are to blame. Does it follow that these should be phased out as soon as possible? Many of us would answer 'yes'. But before we do, we should reflect on the broader picture. The aims of this presentation are to begin this undertaking, adduce relevant ethical principles, and to draw conclusions which are not invariably the ones that we might well adopt prior to reflection. First, can we phase out diesel engines? With automobiles, this is certainly possible, and it is open to governments to introduce scrappage schemes, encouraging people to trade in their diesel-powered cars and replace them with petrol-powered ones. But even this, as we shall see, is not unproblematic.

Further, most trucks and lorries are diesel-powered, and so are most ships and aeroplanes, and replacing their engines is much more difficult. Leaving things as they are means that the areas near major airports and major ports are potential death-traps. But there is a large technological problem involved in attempts to replace the engines of these forms of locomotion with non-diesel engines. However, some submarines are nuclear-powered, and so it must be possible for ships to be adapted so as to be powered by nuclear energy too. There is also the possibility of improved batteries being made so as to make at least lorries run on electricity. So, the widespread replacement of diesel engines is not entirely impossible. Granted, however, that the greater part of dangerous emissions from diesel engines are from diesel cars, it is worth reflecting on whether these should all be replaced. More specifically, can we continue allowing the roads of our cities to be polluted with nitrous oxides (both nitrogen dioxide and nitrous oxide) and at the same time with particulates, tiny particles which seriously damage the respiratory systems of many people.

I personally avoid walking along a quite pleasant stretch of urban roadway, and choose instead a parallel back alley, because it is shielded from the emissions of the road by a row of buildings.
Admittedly it is bordered by a railway of which the trains are powered by diesel fuel; but the trains are not running all the time, unlike the cars of the roadway. Yet schemes to replace diesel cars often involve replacing them with petrol-powered vehicles, and these make a greater contribution to climate change in the form of global warming than diesel engines do. If we compare these two systems for the propulsion of road vehicles, we find that, while diesel cars cause an average loss of life expectancy for people of the present of (on average) a few days or weeks, petrol-powered cars cause harm not only to the people of the vicinity but also to distant people (and often people who have contributed little or nothing to the problem), to our children and our children's children, who will have to endure freak weather events such as floods, hurricanes and fires of an increasing intensity and frequency, and to nonhuman creatures both of the current generation and, if they are able to survive that long, of future generations too.

It should be granted that cars with modern diesel engines are less bad than older ones, and similarly that some cars with modern petrol engines have a much better petrol-consumption rate than the gas-guzzlers of yesteryear. So, the replacement of (say) an old diesel car with a modern petrol-powered car may reduce the overall level of harm. Yet this does little to help attain the target of the Paris Agreement of December 2015, which was to limit the increase in average temperatures to no more than 1.5 degrees Celsius (UNFCCC 2015). (Many people continue to represent the target as a 2-degree ceiling, but in fact the conference agreed to aim at a 1.5-degree ceiling if possible.) So if the choice were between a system for cars propelled by diesel and one of cars propelled by petrol, there may be little to choose between them. Diesel cars mean illness for many of our contemporaries, and a much earlier death for some, and this appears intolerable both at first sight and also, in many countries, politically. But petrol-driven cars involve harms at least as bad for distant people, for future people, and for non-human species; and this is surely just as intolerable ethically, even if in places it is more tolerable politically.

Perhaps, then, we should be advocating the replacement of diesel cars with electric cars, and at the same time the introduction of these in place of petrol-driven cars as well. But before we opt for this solution, we need to reflect on the kinds of system that 
this proposal involves. If, for example, electric cars are powered by electricity generated from coal, oil or gas-powered generating facilities, then the problem is not solved, but merely moved along from city centres and trunk roads to power stations, and their worldwide impacts. This change is in fact comparable to the change once made in Britain when the fuel burned in domestic and industrial fires was changed to smokeless fuel, except in those districts where the factories were situated where ordinary coal was rendered smokeless, through the emission of all the kinds of smoke that smokeless fuel avoided upon the workers and their families. (Many of these were located in the Welsh valleys, not far from where I live.) The change, then, is only likely to be beneficial if the electricity with which electric cars are propelled is generated from renewables, whether solar, hydro-electric, tidal, wind-powered, or wave-powered.

Otherwise moving away from the use of diesel just means replacing harms to current humans with more widespread harms to a greater number of spatially or temporally distant humans and to multiple non-human creatures as well. Some car use could, of course, be replaced through more people choosing to walk or to cycle; but, while these commendable forms of transport are available for fit and healthy people travelling short distances, ideally in good weather, they are not available for the others, nor effectively for travel of more than a few miles. Yet changing from carbon-based electricity to electricity generated by renewables is not without its costs. For the renewable sources themselves have to be manufactured, whether solar panels, tide-driven turbines, windmills that drive electric dynamos or comparable devices and installations. And prior to this transition, the energy consumed in their production has to be derived from non-renewable sources. This consumption of non-renewable energy used to seem small enough to be overlooked, in the days when renewables accounted for only a small proportion of energy generation, But if we are to generate the majority of our power from renewable sources, the amount of energy required to manufacture the necessary equipment comes to assume massive proportions. On one estimate, this would require fifteen percent of the total of non-renewable energy currently generated [2].

There is, of course, a beneficial aspect to this operation of manufacturing equipment needed for renewable energy generation, and this includes the employment that this process will or would involve. Beyond the mere fact of more families having a source of income, these jobs, like most jobs, could be managed in such a way as to constitute worthwhile work, with the workers exercising skill and judgement, and sharing in work-related decisions. Besides, whole communities whose central activities such as mining or shipbuilding have disappeared could be given a new lease of life, and so there could be considerable social advantages as well. Yet either the energy diverted to the manufacture of renewables would have to be diverted from something else, or there would have to be an actual increase in the generation of electricity from non-renewable sources, and one which would be quite considerable, albeit possibly temporary.

These reflections are sufficient to show that there is a downside to all the systems available to power homes, factories, cars and other forms of transportation, whether diesel-driven, petrol-based or even those focused on renewables. In face of this problem, it is tempting to adopt the ethical approach that we should adopt or retain whichever system does least harm; and that may in some cases mean retaining diesel-powered vehicles, in some the use of petrol-driven vehicles, however efficient, and in others resort to renewable technology, however carbon-intensive the manufacture of the relevant equipment may prove to be. The harms of retaining diesel-powered and petrol-powered transport are in different ways predictably adverse to human and non-human health; but so too (surprisingly) would be any wholesale transition to renewable energy.

This approach, of selecting the option that does the least harm, will appeal to many. For example, those who maintain that our first priority must be to prevent any derogation or infringement of human rights may take the view that the harms inflicted by carbondriven climate change are unacceptable, and that even if they can be reduced in extent, they remain intolerable. Large numbers of innocent parties, who have not themselves generated carbon emissions of any significant volume, are adversely affected, whether through rising sea-levels, or through the increasing intensity and frequency of extreme weather events such as fires, floods, storms and hurricanes; and this infringement of their human rights is so unacceptable that we must eventually move to renewables, and in the meantime endure the adverse effects of diesel engines, with their lower impact on global warming. On the other hand, the impacts of diesel use also infringe human rights, and so too may increases in the manufacture of renewable generation equipment using non-renewable energy sources.

While I agree that we must move to renewables (unless nuclear fusion unexpectedly proves viable), I do not agree on these grounds; nor do I agree that we should retain the use of diesel engines any longer than necessary. But I want to raise doubts about the principle that we should invariably adopt the policy option that does the least harm, whether this is related to human rights infringements or not. For while harm and human rights infringements are morally important, they are not the only morally relevant factors. Just say that we could prevent people being harmed, but only at the expense of allowing humanity to go extinct. The price of continuing the human race is almost certainly that there will be at least a small minority of people whose lives are either not positively worth living or actually worth not living. Confronted with this choice, adherents of the principle that we should adopt the policy option that does the least harm would have to say that humanity should be allowed to go extinct; or they would have to do so unless they could somehow argue that non-existence is a harm, a claim that sounds highly implausible. But this choice would be worse then genocide, and would curtail the entire human prospect; future people, with all their potential for art, literature, music and other forms of selfexpression would be precluded from having any chance to develop their potential.

Most people would, on reflection, reject this choice. But to reject this choice involves rejecting the principle that underlies it, namely that it is morally mandatory to adopt the policy that does or causes least harm. This argument is based on a modified 
version of a thought-experiment of the Canadian philosopher John Leslie, which I have presented in The Ethics of the Global Environment. I will replicate the relevant passage here: On each of numerous inhabitable planets, capable of supporting a large human population, whose members would probably lead lives of positive quality, there will also be a person whose life will predictably and inevitably be of negative quality. For the purposes of the thoughtexperiment, these large human populations can be brought into existence by waving a magic wand. Should this be done? For consequentialists who believe in optimising the balance of intrinsic value over intrinsic disvalue [if you are not used to these terms, replace them with 'the balance of good over bad'], and in counting every actual and possible life as having moral standing, the answer is affirmative, even though the resulting population of each planet includes a life of negative quality.

But theorists who prioritise the prevention of misery would have to hold that the answer depends entirely on whether the life of negative quality on each planet can be prevented; if it cannot, then none of these lives should be engendered [3]. Since this thoughtexperiment as so far presented has nothing to say about the quality of non-human life, there follows a passage (in my text) about the quality of life of non-human creatures. But for present purposes I will leave out this complication. The upshot is that, whether we are consequentialists of not, most people agree that we should promote and foster worthwhile lives, even if doing so involves the risk of generating a minority of miserable lives at the same time. In the thought experiment of John Leslie, of which my own thought-experiment is a variant, the miserable lives were each led in windowless habitations, unable to be ameliorated or in any other way affected by their human contemporaries [4]. Thus they were not harmed by these people, but arguably they were harmed by the decision to bring into existence the entire populations of which they form a hapless small minority. Nevertheless Leslie concludes that it would be right to bring these large populations into existence (granted enough habitable planets on which to do so). We might well wish to add the stipulation that the human populations of these habitable planets neither harms nor renders extinct their nonhuman populations; and, to sustain Leslie's thought-experiment, let us accept this stipulation on his behalf.

This thought-experiment cannot on its own be used to clinch the case for consequentialism [5]. But it does, I suggest, establish that moral choices should take into account the good as well as the bad impacts of action, and that the fact that an action has some bad impacts does not of itself make rival options superior. And if so, we should not decide energy policy simply on a basis of minimising harms or evils. (For present purposes, let us set aside the difference between harms and evils, although I have written about this difference at length elsewhere.) Hence, we should take into account the good or the positive value that one or another policy can bring about, and not only the costs, harms or evils to which it may give rise [6-10].

However, maybe the real point behind the suggestion that we should adopt the policy that does the least harm is that we should include foreseeable harms in our policy deliberations, as well as foreseeable goods. With this amendment made, I am strongly inclined to accept the revised suggestion. Thus the costs of renewables should be figured into our reflections about changing to renewables, while the benefits of the use of diesel engines should not be neglected either. Nor should we neglect the comparison between the harms likely to flow from a policy of retaining diesel engines and the arguably greater harms that would eventually flow from replacing them with vehicles propelled by petrol.

But, this said, the mere fact that we can envisage an even worse system for transport than one based on diesel engines does not really support retaining the diesel-based system. Both systems, it should be acknowledged, facilitate enormous amounts of good, through broadening people's experiences, facilitating conferences, and unleashing human creativity, as well as making possible trade and also transporting the casualties of accidents to clinics and hospitals and thus (often) 'giving them their life back', as a friend of mine said after her husband had undergone a successful operation. If these were the only possible systems, then it might after all be right to persist in using diesel engines of the least polluting kind, thus minimising suffering and facilitating all the good that travel and transportation allow of.

However, other systems are possible, and, despite their costs (such as the consumption of possibly 15\% of non-renewable energy [11] on producing the equipment to generate renewable energy), they are capable of facilitating the many goods that existing systems support, plus, in the long run, extending the lives of the people who might have died an early death from either diesel fumes or the multiple impacts of global warming and climate change.

Besides, the consumption of non-renewable energy involved in introducing a comprehensive system of renewables is a temporary problem. For once a comprehensive system of renewably generated energy is in place, the equipment needed to supply it with spare parts and to modify it in the light of new technological developments can itself be manufactured through the use of renewable energy. And renewable energy can then be used for as long as rivers flow, tides ebb and flow, and the sun's radiation continues to reach our planet. Hence, the down-side of the introduction of a comprehensive system of renewable energy generation does not count conclusively against introducing it.

This, then, is how I remain able to advocate the replacement of diesel-powered vehicles with a better system. It is true that advocacy of the replacement of diesel power by petrol power suffers from the limitations of short-termism, because it would mean the extension of average life-expectancy of the inhabitants of modern cities at the cost of disrupted lives and early deaths for many people who are temporally or spatially distant (or both), plus the avoidable extinction of many non-human species. Our focus should instead be on the replacement of diesel and petrol-driven cars with electric cars, and the replacement of carbon-based electricity generation with generation from renewable sources.

Some people, it is true, would advocate instead the replacement of carbon-based electricity generation with nuclear-generated electricity, having nuclear fission in mind. But advocacy of this kind 
is also subject to short-termism. For there is no known safe way of disposing of nuclear waste products, nor of decommissioning defunct nuclear power stations, and so the risks of nuclear contamination from these sources are inflicted by the decision to instal such a system upon future generations for thousands of years to come. It may be possible to limit the risks with respect to nuclear-powered shipping, such as burying decommissioned nuclear-powers ships in deep ocean trenches, but the risks inherent in the operation of nuclear power stations are so significant and so long-lasting as to count strongly against the introduction of systems of nuclear energy generation, quite apart from the risks of nuclear explosions such as those that took place at Three Mile Island and at Fukushima.

Thus the system to be preferred to carbon-based electricity generation has to be one based on renewables, for both moral and practical reasons. Only such a system overcomes the underlying costs of introducing electric cars. This may suggest to some that we should not move to electric cars, or away from diesel cars, until the transition in methods of generating electricity is complete. But this is to ignore the transition period required for people to get used to using electric cars, a period which may well take several decades. It is also to ignore the way in which the introduction of electric cars is likely to encourage public opinion to put pressure on governments to replace conventional energy generation with generation from renewables.

The price of renewable energy is constantly falling, making the introduction of renewable energy facilities all the more feasible. At the same time, the human carbon budget is shrinking, which means that the replacement of carbon-generation with renewable energy has become urgent. If action is not taken soon enough, it will become impossible to halt the increase in average temperatures below the 1.5 degrees agreed at Paris, or even below the Paris fallback position of 2 degrees [12]. This being the background, it becomes imperative to move away both from internal combustion engines propelled by petrol and at the same time from dieseldriven cars, which, although they contribute less to global warming, spread disease and early death in exchange for the many benefits of easy transportation [13].
Indeed large energy companies are already moving into the production of electric cars. This granted, it would be perverse to persist in retaining diesel cars on the basis that changing to petrol cars would make matters worse. As soon as it is feasible, we should make the change to electric cars, and join in pressing governments to make the change to renewable energy generation. Retaining diesel cars would serve to diminish that pressure, while making the change would enhance it. That way lies the road to living within humanity's carbon budget, and thus to saving coastal settlements and islands from flooding, and to preventing wildfires, storms, floods and hurricanes from becoming intolerably frequent and intense.

\section{References}

1. John Vidal (2016) Pollution has risen 8\% in last five years, WHO data show, The Guardian.

2. McMahan, Chris (2017) Conversation of 14 December 2017 at Schumacher Institute, Bristol.

3. Robin Attfield (2015) The Ethics of the Global Environment. $2^{\text {nd }}$ edn, Edinburgh University Press, Edinburgh, United Kingdom, p. 72

4. John Leslie (1996) The End of the World: The Science and Ethics of Human Extinction Routledge. New York, USA

5. A fuller case is presented at Robin Attfield, Value, Obligation and MetaEthics, Leiden: Brill, [1995] 2018, and at Robin Attfield, "The Shape of a Global Ethic', Philosophy \& Social Criticism 32(1): 5-19.

6. Attfield, Robin (2006) 'The Shape of a Global Ethic', Philosophy \& Social Criticism. 32(1): 5-19.

7. Attfield, Robin (2014) Environmental Ethics: An Overview for the Twenty-First Century, $\left(2^{\text {nd }}\right.$ edn), Polity Press, Cambridge, UK.

8. Attfield, Robin (2015) The Ethics of the Global Environment ( $\left.2^{\text {nd }} e d n\right)$, Edinburgh University Press, Edinburgh, UK

9. Attfield, Robin (2018) Value, Obligation and Meta-Ethics. Brill, Leiden Netherlands.

10. Leslie, John (1996) The End of the World: The Science and Ethics of Human Extinction. New York, Routledge, USA.

11. McMahan, Chris (2017) Conversation of 14 December at Schumacher Institute, Bristol.

12. UNFCCC 2015.

13. Vidal John (2016) Pollution has risen 8\% in last five years, WHO data show, The Guardian. 